[Bourke, R., \& O'Neill, J. (2009). Professional Development For Ethical Teaching. New Zealand Annual Review of Education, 18, 107-122]

\section{Professional Development For Ethical Teaching}

\section{ROSEANNA BOURKE AND JOHN O’NEILL}

\section{Abstract:}

The routine dilemmas faced by teachers sometimes provoke heated reactions from colleagues, government and sections of wider civil society as to their practical resolution. Everyday tensions of teaching can produce polarised views about the ethics of decisions and actions that are taken in workplace contexts. How do teachers reach solutions and determine their own "right" or "best" answers to these dilemmas? Using the case of a professional development programme to raise awareness of the New Zealand Teachers Council Code of Ethics for Registered Teachers, this article illustrates how working through a range of carefully constructed, authentic, polarising real-life scenarios allows teachers to safely learn to challenge their assumptions, values and beliefs rationally. The learning process also helps teachers to articulate their tacit theories of "good" teaching practice (including curriculum and assessment), and permits them to justify their decisions and actions based on sound reasoning according to shared ethical principles and commitments.

$\mathrm{L}$ earning to teach in challenging circumstances has long been known to require a skilful balancing of the practical requirements of "control" and "education" (Connell, 1985) and knowledge of how these may meaningfully be manifested in the actual language, practices and relations of the classroom (Kemmis \& McTaggart, 1988). The daily work of teaching is complex, fluid and dynamic. Teaching provides frequent practical dilemmas or tensions for teachers about what is the best way to maintain the required control-education balance with this group of students at this time in this particular educational context (Campbell, 2003). Increasingly, however, teachers are called to account both internally (to colleagues, senior teachers and managers) and externally (the local and state educational communities) for their decisions and actions regarding the "right" or "best" way to resolve the

\section{Roseanna Bourke and John O'Neill}

dilemmas and tensions they face. In turn, this creates an imperative for them to be able to articulate the rationality for what they do. At heart, this is an issue of both morality (knowing what is right/wrong, good/bad and why) and the applied ethics of teaching (the capacity to justify in a reasoned way how specific decisions or actions achieve the most good).

The statutory professional body for teachers, the New Zealand Teachers Council (NZTC), developed a Code of Ethics (New Zealand Teachers Council, 2004) for members, to encourage greater understanding of, and commitment to, ethical teaching practice. We were members of a university-based team of teacher educators that was subsequently commissioned by NZTC to design, run and evaluate a pilot series of eight professional development (PD) workshops in early 2007, to introduce teachers to the Code and to assist teachers to explore issues of practice in relation to ethical dilemmas associated with being a teacher.

The first part of the article outlines the development of the pilot workshop, Ethics into Practice, on the NZTC Code for early childhood, primary and secondary teachers, including the principles of teacher learning about ethical practice that informed its design. It also describes the two practical models of applied professional ethics that were used to provide a systematic framework for the analysis of ethical dilemmas by teachers in the pilot workshops. The second part of the paper reports on the conduct and evaluation of the workshop: it describes the participating teachers, summarises the results of the workshops, and provides an overview of the participants' interactions with the workshop structure and content. In the conclusion we report on the extent to which the NZTC has "scaled up" this education programme since the pilot workshops, and comment on what, in our view, needs to be done to "embed" ethical decision-making more firmly in teachers' routine practice, based on the Code.

\section{The NZTC Code of Ethics}

In December 2004 the New Zealand Teachers Council developed and published a brief, single page Code of Ethics that was premised on aspirational behaviour by teachers, governed by four ethical principles (autonomy, justice, responsible care, truth) and four moral commitments (to learners, parents and families/whanau, society, the profession). While the teacher union and association groups had in earlier years developed their own codes of conduct (primary and secondary) or ethics (early childhood), these covered all members, including support staff 
and para-professionals in education. The NZTC Code was written specifically for teachers across the early childhood, primary and secondary sectors, providing a framework for registered teachers and those granted a Limited Authority to Teach.

The NZTC Code was written following a summit held in 2003 and two national consultation exercises undertaken by the Council in 2003 and 2004. At the summit, presentations were made by Ivan Snook (2003), Alan Hall (2003), Paul Rishworth (2003) and Sue Cherrington (2003). A writers group, including Hall and Snook, was then contracted to consider all the material prepared by the earlier Teacher Registration Board working party and prepare a written report for the Council on a consultative process, together with a draft Code, which it did in July 2003.

The first draft of the Code was circulated for consultation in September 2003. Significantly, this first draft included "matters which a teacher 'will' do and matters which a teacher 'will not' do" under the headings of "duties" to students, parents and families, society and the profession (Snook, 2005). In other words, the first draft advocated a rules- or duties-based Code of Ethics, similar in approach to the Code of Ethics for Psychologists Working in Aotearoa/New Zealand, 2002.

In 2004, a further consultation was undertaken on a greatly revised second draft of the Code in which specific "duties" were replaced by broadly defined "principles" and "obligations". The NZTC distributed a Code of Ethics Workshop Kit nationally as part of its second consultation, Towards a Code of Ethics (New Zealand Teachers Council, 2004). The kit included introductory statements from the Council on the purposes of the Code and professional values and principles, eight video scenarios covering a range of ethical dilemmas in teaching, structured guidelines for running a discussion workshop and a consultation response form. The background reading comprised a reprint of the Rishworth address to the 2003 summit and an abridged article by Alan Hall and Russell Bishop (2004) on teacher ethics, professionalism and cultural diversity. The second draft of the Code was very similar to the eventual gazetted version. The "principles" remained the same but the "obligations" in the second draft were later to become "commitments" in the final Code.

Snook (2005) was highly critical of the final version of the Code, which he argued had resulted in a softening of the original requirements on teachers to act ethically, as a result of vigorous lobbying by the teacher unions around the first draft. Specific duties, Snook suggested, had been replaced by vague, aspirational statements which in his view rendered the final Code "bland" and "inadequate".
The NZTC Code, then, was designed to assist teachers examine their own and others' ethical practice, but the text gives no practical guidance on how to do this. As an aspirational Code grounded in principles and commitments, not rules, it neither prescribes nor proscribes particular teaching behaviours.

As part of an initiative to aid early childhood, primary and secondary teachers develop a greater awareness and a more comprehensive understanding of the Code of Ethics, the NZTC sponsored a series of national training workshops in 2007, developed by a research team at Massey University. The purposes of the workshops were to: (i) create a more comprehensive understanding of the Code with regard to both teachers and learners (students); (ii) provide teachers with facilitated learning support to begin to apply the Code in practice and in context; and (iii) develop a shared understanding about the practical implications of the Code for both teachers and learners.

The literature on teaching applied professional ethics ( $\mathrm{O}^{\prime}$ Neill \& Bourke, in press) has consistently argued that if teachers' practice is to become more ethical, it is necessary but not sufficient for them to know what ethics are in an abstract sense. Campbell (2003), for example, notes that often unquestioned aspects of routine, day-to-day teaching create serious ethical challenges for teachers. If teachers have limited ethical knowledge, they may well be morally uncertain about what to do in particular situations, however familiar. Moreover, it is the specific context that creates the ethical dilemma. Form-filling and recordkeeping, for instance, are unremarkable aspects of the teaching role. However, specific requests to provide or retain certain types of information may create a dilemma. For Campbell, unless teachers have a strong moral and ethical foundation to guide decisions about their practice, they are less likely to be able to apply conflicting precepts of right and wrong in a situation, in order to decide on a principled course of action. As a result, they may end up avoiding or managing the situation rather than practically resolving the ethical dilemma. Campbell would argue that this means teachers are in danger of compromising their beliefs and values and, as a result, losing self-confidence and esteem little by little. Instead, as Peters puts it, teachers must learn to "act after deliberation without being paralysed by indecision" (1973, p. 36).

Accordingly, the Massey research team decided that, in addition to the required "awareness-raising", the PD model adopted for the workshop must also accommodate the knowledge that: (a) learning to be ethical is not about the application of abstract rules or "cookbook" 
approaches, but gaining experience of solving practical ethical problems rationally; (b) ethical problems are by their nature complex with more than one possible solution, requiring a systematic approach by the teacher to frame and consider the dilemma; (c) in addition to the principles and commitment embodied in a Code, teachers must come to know their own personal moral character, their beliefs and values as a teacher, and their assumptions about the world; and (d) the specialised language and processes of ethical reasoning are not typically part of teachers' day to day language and thinking.

This kind of learning takes time, however. Therefore it was decided by the research team that in an introductory one day workshop of the type commissioned for this project, the most that could be achieved was to introduce teachers to the basics of ethical thought and action (this part of the workshop was subsequently called "relating ethics to practice", see below), provide simple frameworks to encourage, shape and facilitate ethical thinking ("identifying ethics in practice"), create opportunities to apply this thinking to a range of situations that call for ethical action ("locating ethics in practice"), and, in all of these, to ensure meaningful discussion of the need for rational ethical thought and action in the various facets of their day-to-day work as teachers.

\section{PD Workshop Structure}

The workshop was developed for teachers across the three sectors: early childhood, primary and secondary. A teacher reference group was used by the research team in the design phase to ascertain practising teachers' likely awareness of the Code and knowledge of ethics, to elicit "realistic" scenarios that teachers might encounter in their work and to gain an idea of the kinds of learning activities teachers might find productive in a single one-day workshop. It was also recognised that participating teachers would in some cases be expected to lead follow-up PD in their own educational setting. Accordingly, a pack of reading material related to the models and theories used in the workshop design was compiled, and an open-access website $<$ http://ethics4teachers.massey.ac.nz/ $>$ was created to include down-loadable.MPG files of the digital moving image scenarios and the Powerpoint slides used by facilitators in the workshop.

The first session involved an explanation of what "ethics" is, including the difference between a genuine ethical dilemma and a hard but unpalatable decision. In this session, teachers were also given an overview of the NZTC Code. The second session focused on the systematic analysis of situations that pose complex ethical dilemmas, including bicultural and multicultural educational scenarios. The third, afternoon, session, comprised "break-out" activities in which groups of teachers analysed realistic scenarios using the NZTC Code principles and commitments. This was followed by a plenary session.

The workshop was organised around scenario-based professional learning underpinned by two key ethical decision-making models: (1) an activity based on Kidder's model (1995), which has previously been applied in early childhood teacher education, to introduce ethical analysis; and (2) Newman and Pollnitz's (2002) Ethical Response Cycle to analyse ethical scenarios.

\section{The Kidder model}

Kidder's (1995) model of ethical analysis has been used as a framework for practitioners in educational settings (Newman \& Pollnitz, 2002) as well as other occupational contexts, such as journalism and public relations (Tilley, 2005). The model offers a simple technique to determine whether or not an issue is in fact an ethical dilemma through the use of three questions or tests that focus the user's thinking about a "right" versus "wrong" scenario.

Beginning with plain language and everyday analogies to make the underlying moral reasoning accessible, Kidder suggests there are three tests that can be applied to a moral issue to identify right versus wrong issues:

- The stench test asks: Does the issue have an odour of corruption that makes others look askance? Does it go against the grain of moral principles? The stench test is a form of moral reasoning that asks about moral principles rather than consequences. It concerns doing what is right without consideration of consequences.

- The front page test asks: How would you feel if what you were about to do was in the headlines of tomorrow morning's newspaper? The front page test involves ends-based reasoning focused on negative outcomes. It is based on the utilitarian principle, i.e., what would bring the greatest good to the greatest number?

- The Mum test asks: If I were my mother (or any other moral exemplar) would I do this? The Mum test involves care-based reasoning, putting yourself in the shoes of others. It involves the Golden Rule - do unto others as you would have them do unto you. 


\section{Newman and Pollnitz's ethical response cycle}

Newman and Pollnitz's (2002) Ethical Response Cycle is presented as a diagrammatic representation of a reflective and analytic process that can be used to reason one's way through ethical scenarios to the point of taking a decision. The cycle acknowledges that personal beliefs, professional and legal considerations all need to be identified as part of ethical decision making. The cycle commences with recognition of the dilemma followed by reflection on personal competencies and beliefs as well as initial considerations regarding the outcome of any decisions and action. Subsequent phases in the cycle comprise consideration of: legal aspects, professional considerations, ethical principles and theories, informed inclination (professional dispositions, knowledge, and experiences), judgement, actions and documentation of the process and any implications for further action. The Ethical Response Cycle is "used as a framework to support and validate systematic and sensitive reasoning, by considering each of its phases, for every situation under consideration" (Newman \& Pollnitz, 2002, p. 116).

\section{Workshop Evaluation}

Consistent with the workshop design rationale, formative and summative evaluation occurred throughout the series of eight national PD days, delivered in a number of ways: immediately prior to the workshops, during the workshops, immediately after each workshop, and through probes with individual teachers randomly selected from the workshop participants from each location two or three weeks after the workshops. The facilitators also kept a reflective journal throughout the workshop series.

The formative evaluation was used to make adjustments to aspects of the workshops in order to better meet the needs of teachers. Formative feedback was used throughout to fine-tune and support the development of the series. The summative feedback was to evaluate how the teachers perceived the workshops once they had participated in them, through written evaluations. Follow-up email probes were conducted three weeks after the workshop, involving a selection of teachers from among those who had agreed to be contacted. The probes represent 12 percent of the total attendees, and these teachers were selected to ensure feedback was gained from each sector and that all eight workshops were represented. In total, 52 invitations to provide further evaluation responses were sent out via email with the invitation for teachers to either email back a response or request a telephone interview. Twenty-seven teachers responded by email, providing another source of data. Owing to constraints of space, however, only the quantitative evaluation data together with facilitator reflective observations are reported in this article.

\section{The participating teachers}

Eight workshops were conducted in the North and South Islands towards the beginning of the year, in February and March 2007. A total of 227 teachers attended the workshops and the number of participants in each workshop ranged from 11 to 41 .

One hundred and ninety seven workshop participants responded to the evaluation questionnaire; $87 \%$ (171) were female and $13 \%$ (26) were male. The majority were experienced teachers, with almost half of them reporting they had been teaching for over 21 years. Only $11 \%$ of participants reported their teaching experience to be in the 0-5 year bracket. The highest proportion were early childhood teachers $(41 \%)$, followed by primary (29\%) and secondary (9\%). Others included specialist teachers, tertiary educators and para-professionals.

\section{Participants' interaction with the workshop structure and content}

All 197 respondents either strongly agreed or agreed that they understood the NZTC Code better after the workshops than before. Similar numbers also reported a high level of belief that their knowledge of ethics and their confidence levels in dealing with ethical dilemmas had increased. Throughout the workshops teachers indicated that their enjoyment of the workshops contributed to their increased confidence and understanding of ethical dilemmas, and that the practical relevance of the NZTC Code supported their decision making.

Participants were asked to rate the effect of the workshops on their confidence in helping colleagues understand how to deal with their ethical dilemmas. All of those who responded reported that their confidence increased; either "increased greatly" (62\%) or "increased a little" (38\%).

At the conclusion of the workshops, participants were asked to rate the extent to which their experience was enhanced by same sector grouping and mixed sector grouping in various activities during the workshop. Seventy-seven percent strongly agreed or agreed that same sector group activities enhanced the workshops, and 83 percent strongly agreed or agreed that mixed sector group activities enhanced the workshops. 


\section{Relating ethics to practice}

The first section of the workshop used a structured Powerpoint presentation to: (a) introduce participants to the concept of ethics in order to provide a basis for understanding the purpose of the NZTC Code; (b) explain the Kidder test as an approach to identifying ethical dilemmas; (c) provide an overview of the NZTC Code through its constituent principles and commitment statements; (d) emphasise the centrality of the principles of the Treaty of Waitangi to ethical teaching; and (e) provide small group discussion opportunities to allow teachers to begin using these when discussing ethical dilemmas provided through scenarios and video clips.

Immediately before each workshop began, participants were asked to select one out of eight possible responses to complete the statement "A teacher is being ethical when he or she ...." The aim of the question was to get an indication of how important teachers regarded reasoning or justification as part of being ethical. Depending on one's personal ethical "position", being ethical as a teacher might be interpreted as "doing the right thing" (response a), not harming others (response b) or "being able to explain how one's actions do the most good" (response f). Arguably, (f) demonstrates the clearest understanding of ethics as the process of arriving at a reasoned decision about what is the right thing to do in a particular situation, taking into account the rights of all those involved. Among the 178 respondents to this question, just five teachers selected response (f), nine chose (a) and two chose (b). Twenty-seven percent selected "Follows the Code of Ethics"(d). A higher percentage (30\%) selected "Handles teaching situations in a professional manner" (c), and a further $30 \%$ selected "Considers the circumstances of the situation before acting"(e). However, it could reasonably be argued that the latter two "effective teaching" attributes are insufficient to ensure that ethical considerations are paramount. Two further responses, also regarded as "insufficient", received low percentages (1\% - 5\%).

Prior to the workshop, participants were also asked to rank order a list of those from whom they most preferred to seek support when dealing with a difficult ethical dilemma as a teacher. By far the most frequent response was "colleague" $(\mathrm{n}=168)$, followed by "professional association" ( $n=79)$ and "partner" $(\mathrm{n}=54)$. When asked how often they referred to the NZTC Code of Ethics (or another written code for teachers) when dealing with an ethical dilemma, 28\% reported they "sometimes" did; with only $1 \%$ stating "always". The large majority $(67 \%)$ answered "hardly ever" or "never" to this item, or did not respond (5\%). On the basis of these data it appears that approximately two thirds of the participants were unfamiliar with the Code before attending the workshop.

Participants were asked to list the four principles of the NZTC Code of Ethics for Registered Teachers prior to the workshop. Eighteen percent could identify the four principles while $10 \%$ identified between 1 and 3 principles; $29 \%$ were unable to identify any principle and a further 84 participants ( $42 \%$ ) did not complete this question, indicating that $71 \%$ of workshop participants may be unaware of the principles. At the conclusion of the workshop, participants were asked to rate whether the four principles, commitments, and scenarios had helped their ability to analyse ethical dilemmas in the workshop. Ninety-four percent strongly agreed or agreed that the four principles had helped, and $93 \%$ strongly agreed or agreed that the commitments had helped.

\section{Identifying ethics in practice}

The purpose of the next section of the workshop was to provide participants with a framework and strategies to encourage, shape, and facilitate ethical thinking. A major component was the introduction and explanation of Newman and Pollnitz's (2002) ethical response cycle. After taking notes on the ethical response cycle diagram provided, participants discussed amongst themselves situations they had encountered where "knee-jerk" and more considered analysis had been applied. They were asked to consider what aspects of the ethical response cycle were involved in the latter and would have benefited the former.

The NZTC (2004) "laptop liability" video clip was then shown. In this, a teacher borrows her colleague's laptop when her computer crashes. She discovers that her colleague has a number of pornographic sites featuring teenage girls listed in his website "favourites" list. While it is not a school computer and he is using it in the privacy of his own home, she questions what her discovery says about her colleague's attitude to women and his professional behaviour.

The clip was analysed using the response cycle framework. The subsequent whole group discussion highlighted the complex nature of the dilemma and the usefulness of the ethical response cycle in "teasing out" and considering the complexities involved. This multi-faceted consideration required participants to move beyond initial gut reactions or decisions based solely on personal or professional "informed inclination" to an appreciation of the many factors that should be taken 
into account when making ethical decisions. The NZTC Code of Ethics was emphasised as an important component of the ethical response cycle.

The clip provoked intense and heated discussion in all workshops. Issues arose in relation to: (a) the right of the teacher to inform a colleague of her suspicions around another named colleague; (b) the right of the teacher to open up files on a computer that were not intended for her viewing; (c) the right of a teacher to discuss issues of a sensitive and confidential nature in a staffroom situation; (d) the implications of a teacher viewing objectionable material; and (e) the obligation to avoid harm by protecting the confidentiality of colleagues. Some teachers within the workshops believed that "what a teacher does in his or her own time does not impact on their teaching", while other participants voiced strong opinions that teaching is a profession that requires strong moral values to be upheld throughout one's personal and professional life. In their discussions of this specific teaching scenario, many teachers identified talking (in the staffroom) with a colleague as an inappropriate means of support.

Participants argued that it was inappropriate for teachers to talk with their colleagues and discuss other teachers' behaviours, and that a systematic process should have been adhered to when there were concerns about a colleague's behaviour. However, prior to the workshops, teachers rated their colleagues twice as likely to be sources of support when dealing with ethical dilemmas. This is an area that could be further examined, because it is difficult to ascertain from these data whether teachers used colleagues in a structured, supervised format when seeking support, or whether they were referring to informal "staffroom chatter".

The second part of this section of the workshop was devoted to an analysis of cultural awareness and ethical dilemmas. Participants discussed examples of dilemmas they had faced with a specific cultural component. These included bicultural and multicultural scenarios.

\section{Locating ethics in practice}

In this section of the workshop, participants were provided with opportunities to apply the frameworks for ethical analysis (Kidder, Ethical Response Cycle, cultural awareness) and their understandings of the NZTC Code (principles, commitments, Treaty of Waitangi obligations) to which they had been introduced in the first two sessions, to the more detailed analysis of a range of situations that call for ethical action.
Prior to the workshop, participants had been asked about confidence in their ability to deal with ethical issues that concerned their own practice, students, colleagues, whanau/family and educational agencies. After the workshop, they were asked (i) whether the principles, commitments and scenarios had helped them to analyse ethical dilemmas and (ii) about their overall confidence in dealing with ethical dilemmas and in helping colleagues to understand how to deal with ethical dilemmas.

Before the workshop, $96 \%$ of those who responded were confident $(76 \%)$ or very confident in their ability to deal with personal ethical issues, and only $4 \%$ unconfident. Ninety two percent were confident $(69 \%)$ or very confident in dealing with ethical issues involving students, $8 \%$ unconfident. Eighty percent were confident $(72 \%)$ or very confident in dealing with issues involving colleagues, and $20 \%$ unconfident. Eighty two percent were confident (70\%) or very confident in dealing with issues involving whanau/family, and $21 \%$ unconfident. Seventy eight percent were confident $(67 \%)$ or very confident with ethical issues involving educational agencies and $22 \%$ unconfident or very unconfident. After the workshop, all those who responded agreed $(46 \%)$ or strongly agreed that their confidence in dealing with ethical dilemmas had increased, and all also agreed (38\%) or strongly agreed that their confidence in helping colleagues understand how to deal with their ethical dilemmas had increased.

Participants were given copies of the NZTC Code, together with a selection of sector-specific scenarios, and asked to work in sector groups to analyse a dilemma of their choice using the principles and commitment statements. Overhead transparencies were provided to groups on which they could summarise their discussions when reporting back to the whole workshop.

A set of diverse scenario cards for early childhood, primary and secondary teachers was developed, with cultural inclusion incorporated across the scenarios. Some were sourced from the New Zealand Teachers Council (2004) videotape, with the majority developed by the Massey University project team. The primary aim of the scenario-based training was to use examples, situations, and stories that were real for teachers in their experience, while not necessarily being authentic examples of their own everyday practice. Teachers had also been invited to contribute further scenarios from their own practice (via the Massey University website when they registered for the workshops). The website anecdotes were referred to during the workshops when 
appropriate but not formally incorporated into the developed scenarios. A matrix was developed for each sector, linking the scenarios with the principles and commitment statements of the NZTC Code of Ethics. The scenarios were placed on A3 cards, laminated and colour coded for each sector group. These were successful and perceived to be of practical use by the teachers attending. Of those who responded to the questionnaire, 99\% strongly agreed or agreed that the scenarios helped analyse ethical dilemmas in the workshop (60\% strongly agreed).

\section{Conclusion}

Unquestionably, teachers must act ethically. The issue is how best to ensure that they do. The Code of Ethics for Registered Teachers has been developed under the auspices of NZTC over several years. The NZTC has statutory responsibilities for both leadership and standards with respect to New Zealand's teachers. Development and implementation of a code of ethics has arguably been its major leadership task to date. As part of this, the Council decided that a professional development workshop would be required to raise awareness of the Code among teachers.

Following the delivery of the eight-workshop pilot reported here, NZTC budgeted for a further eight regional Code workshops in the 2007-2008 financial year, which were attended by 203 teachers (P. Lind, personal communication, January 27, 2009). In 2007, NZTC initiated a tendering process to develop and run workshops for kaiako from Māori medium educational settings, Whakatinanatia i Nga Tikanga Matatika. Four workshops were run by Tihi Ltd. for 75 kaiako. Following its decision to have Council staff run "mini workshops" wherever possible, NZTC ran a further three workshops at sector group meetings, where 40 participants attended (P. Lind, personal communication, January 27, 2009). The Council intends to deliver at least four more Māori medium workshops by June 2009. In total, in 2007 and 2008, 545 registered teachers attended workshops on the NZTC Code of Ethics, out of the 86,000 teachers on its register.

Evaluation of the Ethics into Practice workshops indicates that teachers need ongoing systematic and structured support in beginning conversations around ethical practices, and in challenging views about what is considered "right" and "wrong" in particular contexts. The diverse views explored in the workshops suggest that teachers are identifying the complexities in teaching and are working to clarify the sometimes fine distinctions between an ethical educator and an accountable professional.

Analyses of data confirm that the participating teachers developed an understanding of, and familiarity with, the NZTC Code of Ethics and increased their confidence to apply the Code to their own practice and context. It is the application of the principles and the code in practice that has yet to be explored. Certainly, from the feedback received from the evaluation, teachers appreciated the increased scripted knowledge of what they ought to do.

The workshops involved teachers in discussions and debates that promoted ethical and moral reasoning. For example, issues were raised in relation to teaching, pedagogy, assessment, school and centre infrastructures, as well as teacher, student and family. Contextual and, where appropriate, cultural considerations were identified by teachers and examined as integral factors when working through an ethical dilemma. The provision of professional learning support enabled the participating teachers to become familiar with the NZTC Code of Ethics and to develop a shared understanding of what it means to engage in ethical decision-making.

Initial levels of teacher knowledge and awareness of the Code were relatively low, as was participants' expertise in analysing teaching dilemmas ethically. The Council's response to this evaluation finding has been to modify the Graduating Teacher Standards and Registered Teacher Criteria, and to seek to work with initial teacher education providers and those offering induction and mentoring pilot programmes for provisionally registered teachers, in order to raise the profile of the Code. The Council is also of the view that the "cascade" model used in the Massey workshop permits participants to in turn provide workshops for teachers in their own institutions (C. Shaw, personal communication, February 27, 2009).

Our experience of designing and delivering the workshop suggests that it is possible to support "ethics into practice" successfully but that this is a longer and more complex process than can reasonably be addressed through a one-day workshop. Some of this process is inevitably organic - as knowledge of and commitment to the Code become more widespread among teachers, it will inform the ways in which teachers frame and address ethical dilemmas in their day-to-day work.

However, given the numbers of registered teachers in New Zealand, and the fact that after two years, considerably less than one percent of 
registered teachers have received formal education in the Code, serious attention needs to be given to the issue of how best to ensure that teachers are educated to act ethically.

\section{Acknowledgement}

Other members of Massey University involved in the project were Jill Bevan-Brown, Janis Carroll-Lind and Joy Cullen. The teacher reference group comprised volunteers from schools and early childhood centres. The project was funded by the New Zealand Teachers Council, which also established an advisory group of professional and academic members to provide feedback on the workshop design during its development phase.

\section{References}

Campbell, E. (2003). The ethical teacher. Maidenhead: Open University Press.

Cherrington, S. (2003, March). Ethics in early childhood. Presentation to the Teachers Council Code of Ethics Summit, Wellington.

Hall, A. (2003, March). Notes on a Code of Ethics for New Zealand registered teachers. Presentation to the Teachers Council Code of Ethics Summit, Wellington.

Hall, A., \& Bishop, R. (2004). Teacher ethics, professionalism and cultural diversity. Unpublished manuscript.

Connell, R. (1985). Teachers' work. Sydney: George Allen \& Unwin.

Kidder, R. (1995). How good people make tough choices: Resolving the dilemmas of ethical living. New York: Simon \& Schuster.

Kemmis, S., \& McTaggart, R. (1988). The action research planner (3rd ed.). Waurn Ponds, Vic: Deakin University.

Newman, L., \& Pollnitz, L. (2002). Professional, ethical and legal issues in early childhood. Frenchs Forest, NSW: Pearson SprintPrint.

New Zealand Teachers Council. (2004). Towards a code of ethics. Wellington: NZ Teachers Council.

New Zealand Teachers Council. (2004/2007). Code of ethics for registered teachers. Wellington: NZ Teachers Council.

O'Neill, J., \& Bourke, R. (in press). Educating teachers about a code of ethical conduct. Ethics and Education, 5(2).
Peters, R. S. (1973). Reason and compassion. London: Routledge \& Kegan Paul.

Rishworth, P. (2003, March). The Code of Ethics as shield, sword and guide. Presentation to the Teachers Council Code of Ethics Summit, Wellington.

Snook, I. (2003, March). The ethical teacher. Presentation to the Teachers Council Code of Ethics Summit, Wellington.

Snook, I. (2005, February 17). Watered-down ethics code for teachers is inadequate. New Zealand Herald. Retrieved April 9, 2009 from:

$<$ www.nzherald.co.nz/primary-education/news/ article.cfm?c id $=288 \&$ objectid $=10111322>$.

Tilley, E. (2005). The ethics pyramid: Making ethics unavoidable in the public relations process. Journal of Mass Media Ethics, 20, 305-320.

\section{The authors}

Roseanna Bourke has been a teacher, educational psychologist and researcher and is currently the Director of the Centre for Educational Development for teacher professional learning, research and practice, in the College of Education at Massey University, Palmerston North. She is interested in student voice and in how learners experience and participate in multiple communities and contexts. Roseanna's doctoral research identified how students conceptualise learning and selfassessment in school and in out-of-school contexts.

Email: <R.Bourke@massey.ac.nz>

John O'Neill is based in the School of Arts, Development and Health Education at Massey University, Palmerston North, and has interests in education policy, leadership, teachers' work and learning, and research ethics. His current research is on informal teaching in local communities. John is joint editor, with Paul Adams, of the New Zealand Journal of Teachers' Work.

Email: <J.G.ONeill@massey.ac.nz> 